\title{
Is Duct Excision Still Necessary for All Cases of Suspicious Nipple Discharge?
}

\author{
Michael S. Sabel, MD, Mark A. Helvie, MD, Tara Breslin, MD, \\ Alida Curry, Kathleen M. Diehl, MD, Vincent M. Cimmino, MD, \\ Alfred E. Chang, MD, and Lisa A. Newman, MD, MPH \\ Departments of Surgery (MSS, TB, KD, VC, AE, LAN) and Radiology (MAH), University of Michigan \\ Comprehensive Cancer Center, Ann Arbor, Michigan
}

- Abstract: Despite the low likelihood of malignancy, it is recommended that all women with pathologic nipple discharge undergo duct excision based on the inadequate sensitivity of diagnostic modalities. However, these data originates prior to recent improvements in breast imaging. We performed a retrospective review of patients evaluated in the setting of modern diagnostic breast imaging. Of 175 women referred to our breast clinic with a primary complaint of nipple discharge, 142 $(81 \%)$ had suspicious discharge. Of the 23 patients who opted for observation over duct excision, with a mean follow-up of 3.3 years, none have been diagnosed with cancer. Among patients who proceeded with surgery, cancer was diagnosed in seven patients (5\%). Six of the seven patients had either an abnormal mammogram or ultrasound. Among 46 patients with suspicious nipple discharge, a normal physical exam and normal diagnostic mammogram/ultrasound, only one malignancy $(2 \%)$ was identified in a 79 -year-old patient with a personal history of breast cancer. In selected patients with suspicious nipple discharge, but normal physical exam and diagnostic imaging, short-term observation with repeat evaluation seems reasonable for patients who do not desire duct excision.

Key Words: breast neoplasm, galactography, mammography, nipple discharge, ultrasonography

E valuation of nipple discharge can be frustrating for both patients and physicians. Nipple discharge accounts for approximately $5 \%$ of referrals to breast surgeons (1-3). The causes of nipple discharge are many, the overwhelming majority of which are benign. Physiologic nipple discharge is benign and common. Pathologic nipple discharge is less common and presenting features include unilateral, spontaneous discharge emanating from a single duct, either clear or bloody. However, even among the subset of women presenting with pathologic nipple discharge, the likelihood of malignancy is quite low.

The work-up of the woman presenting with nipple discharge typically begins with a thorough history and physical and directed breast imaging including diagnostic mammography and possibly diagnostic ultrasonography. If the nipple discharge appears physiologic, no further evaluation is indicated (4). For other

Address correspondence and reprint request to: Michael S. Sabel, MD, 3304 Cancer Center, 1500 East Medical Center, Drive Ann Arbor, MI 48109, USA, or e-mail: msabel@umich.edu.

DOI: 10.1111/j.1524-4741.2011.01207.x

(C) 2011 Wiley Periodicals, Inc., 1075-122X/11

The Breast Journal, Volume 18 Number 2, 2012 157-162 patients, abnormal findings identified on physical examination or breast imaging will guide a subsequent diagnostic evaluation. Clinical uncertainty arises in the patient with pathologic nipple discharge and no abnormality on exam or imaging. Conventional wisdom has held that despite the low likelihood of malignancy, these women require surgical excision of the duct(s) to make the diagnosis, either via a central duct excision or a single duct excision. This recommendation is based on the inadequate sensitivity and specificity of imaging or of additional tests, such as cytologic examination of the discharge or ductography. However, much of these data originates from a time when breast imaging was perhaps less sensitive. This study was therefore undertaken to the pathologic findings on duct excision in the setting of modern diagnostic breast imaging.

\section{METHODS}

With IRB approval, we performed a retrospective review of all patients who were evaluated at the University of Michigan Breast Care Clinic with a primary complaint of nipple discharge between January, 1999 
and April, 2008. Patients referred for a documented breast cancer, or an alternate complaint (breast mass, abnormal mammogram), who also had nipple discharge, were excluded. The following data were collected: age, family history of breast or ovarian cancer, characteristics of the discharge (laterality, spontaneous versus expressed, time present prior to evaluation, color, presence of blood), physical exam findings, radiologic work-up and findings, cytology, or pathology results.

Imaging evaluation of pathologic discharge typically included diagnostic mammography and sonography for women over 30 years. Standard mammographic work-up included CC, MLO, lateral, and spot (with or without magnification) views of the retroareolar area. Diagnostic ultrasound was performed using high frequency tranducers of the retroareolar and central breast to assess for breast mass, focal ductal dilation, or intraductal mass. Actual scanning was performed exclusively by dedicated breast imaging radiologists who also interpreted the mammograms. Ductography, if requested by the surgical service, was performed at a later date.

For the purpose of this review, suspicious nipple discharge included any discharge with blood (either by report or a positive guiac), any unilateral, spontaneous clear discharge, or any complaint of discharge in the face of a personal history of cancer or strong family history of breast or ovarian cancer. A strong family history was defined as the presence of a 1 st degree relative with breast/ovarian cancer, multiple non-1st degree relatives or a relative with breast or ovarian cancer at a young age, whereas a moderate family history included any patient with a non-1st degree relatives with postmenopausal cancer. Non-suspicious discharge was bilateral, and expressed only or nonclear, non-bloody discharge in the absence of a family history of cancer. Fisher's exact test was used to determine statistical association, with a two-tailed p-value of $\leq 0.05$ considered statistically significant.

\section{RESULTS}

A total of 175 patients were seen with an isolated complaint of nipple discharge. The patient population had a mean age of $50.4 \pm 13.5$ (range 13-99). Sixtysix patients $(37 \%)$ had no family history of breast or ovarian cancer, whereas $66(37 \%)$ had a moderate family history and $43(24 \%)$ had a strong family history. In 29 patients, the family history remained unknown, either because the patient did not know or the clinician did not record the information.

The characteristics of the patients and discharge are summarized in Table 1 . The majority of patients were referred to the University of Michigan Breast Care Clinic with suspicious discharge (81\%). In $90 \%$ of cases, the discharge was unilateral, and in $74 \%$, it was spontaneous. There was either a report of bloody nipple discharge or a positive guaic test in 120 patients $(69 \%)$. While nearly half of the patients $(42 \%)$ sought medical attention within a month of the onset of discharge, $10 \%$ had the discharge between 6 months and 1 year, and $11 \%$ had the discharge for over a year.

Work-up began with a detailed history and physical examination. A total of 151 patients $(86 \%)$ had either no physical findings or benign findings, such as postsurgical changes from previous biopsies. Seven patients $(4 \%)$ had nipple inversion or retraction. Ten patients had a subareolar mass or subareolar thickening, whereas one patient had a mass detected in the upper outer quadrant of the breast. Four patients $(2 \%)$ had excoriated lesions on the nipple, whereas two patients had dermatologic changes.

Almost all patients had mammography performed. Two patients, both under the age of 30 , did not

\section{Table 1. Patient Characteristics}

\begin{tabular}{lc}
\hline Average age & $50.4 \pm 13.55$ \\
Length of time discharge was present & \\
$<1$ month & $74(42)$ \\
$1-6$ months & $57(33)$ \\
$6-12$ months & $18(10)$ \\
Over 1 year & $20(11)$ \\
Unknown & $6(3)$ \\
Laterality & \\
Bilateral & $18(10)$ \\
Left & $78(45)$ \\
Right & $79(45)$ \\
Spontaneous? & \\
Yes & $130(74)$ \\
No & $45(26)$ \\
Blood & $120(69)$ \\
Yes & $50(29)$ \\
No & \\
Family history & $66(38)$ \\
None & $37(21)$ \\
Moderate & $43(25)$ \\
Strong & $29(17)$ \\
Unknown & \\
Discharge type & $34(19)$ \\
Non-suspicious & $119(68)$ \\
Bloody discharge & $4(2)$ \\
Clear, spontaneous, unilateral discharge & \\
Persistent spontaneous discharge, strong & \\
family or personal history of breast/ovarian cancer \\
\hline Values within parenthesis are expressed in percentage. \\
\end{tabular}


receive mammograms. In 140 cases $(80 \%)$, the mammogram was normal, and in one case the mammographic evaluation was incomplete due to unavailability of prior comparison films. Nine cases had benign or probably benign findings, whereas four cases had only dilated retroareolar ducts. Nineteen cases had suspicious findings; a suspicious mass or asymmetry in one case $(6 \%)$ and suspicious microcalcifications in nine cases $(5 \%)$.

Ultrasonography was performed in 132 cases $(75 \%)$, and was normal in over half (71 patients, $54 \%)$. Benign changes were seen in 15 cases $(11 \%)$ and dilated ducts only were noted in 20 cases $(11 \%)$. A subareolar mass was detected in 11 cases $(6 \%)$, and an intraductal mass or filling defect was detected in 14 cases $(8 \%)$.

Cytology was utilized in four cases. In two cases, it was negative, and both patients ultimately had either an intraductal papilloma or papillary hyperplasia. One patient had atypical cells and had an intraductal papilloma, and in the 4th patient the specimen was insufficient.

Ductography was used selectively, and ordered in $77(44 \%)$ of cases. In 21 of the cases, where a ductogram was ordered, it was not successful, either because there was no identifiable discharge on the day of the ductogram, the duct could not be cannulated, or the duct was cannulated, but the contrast agent could not be injected. In one case, there was extravasation of the contrast. In the remaining 56 cases, 20 ductograms $(36 \%)$ showed no abnormality whereas $33(59 \%)$ demonstrated either an intraluminal filling defect (31) or intraductal mass (2). In two cases, there was ductal dilatation alone, and one case had equivocal findings.

Of the 175 patients seen during this time period, 41 did not go on to have a duct excision or tissue biopsy. Eighteen of these patients had non-suspicious discharge, whereas 23 had suspicious discharge, but essentially negative imaging and opted for observation rather than duct excision. Three patients have no follow-up beyond the initial consultation. For the remaining 20, with a mean follow-up of 3.3 years, there have been no subsequent diagnoses of cancer.

For the other 134 patients, tissue diagnosis was obtained. In two patients, this meant a punch biopsy of a nipple lesion (in one case demonstrating Paget's disease and in one case a benign nipple adenoma). In three patients, this involved a core biopsy of an abnormal mammogram finding. In two of these three cases,
DCIS was diagnosed, whereas the third case revealed apocrine metaplasia and intraductal papilloma. The remaining 129 patients underwent central duct excision. The underlying pathology is summarized in Table 2. Cancer was diagnosed in seven patients. This represents $5 \%$ of the patients having surgery and $4 \%$ of the entire group. The most common diagnosis among patients having surgery $(47 \%)$ was either an intraductal papilloma (59 cases) or papillary hyperplasia (four cases). Fibrocystic changes were present in 26 cases $(19 \%)$ and duct ectasia or inflammatory changes were noted in $17(13 \%)$. Six patients were diagnosed with benign atypias detected (atypical ductal hyperplasia, atypical lobular hyperplasia or LCIS) and eight patients had other benign findings, such as sclerosing adenosis, adenoma, hyperplasia, or lactational changes). Finally, six patients had benign breast parenchyma with no pathologic abnormality detected.

The seven patients who were ultimately diagnosed with cancer are summarized in Table 3 All seven had suspicious discharge, bloody in six cases and a spontaneous, unilateral clear discharge in a patient with a strong family history. In six of seven cases, there were abnormal findings on physical examination or on imaging studies. In one case, a 79-year-old female with a prior history of contralateral breast cancer, physical exam, mammography, and ultrasonography were all normal. The patient did not have a ductogram but, based on her personal history, proceeded to duct excision, which revealed DCIS. Among the clinical characteristics we examined, none (age, family history, length of time of the discharge, bloody versus non-bloody, spontaneous versus expressed) were statistically associated with the presence of cancer.

Table 4 examines the correlation between the mammogram and ultrasound findings and the pathology among patients who did undergo tissue biopsy. There

\section{Table 2. Pathology of 134 Patients who had Tissue Diagnosis}

\begin{tabular}{lr}
\hline Intraductal papilloma & $59(44)$ \\
Papillary hyperplasia & $4(3)$ \\
Fibrocystic changes & $26(19)$ \\
Duct ectasia/inflammatory changes & $17(13)$ \\
Cancer & $7(5)$ \\
ADH/ALH/LCIS & $6(4)$ \\
Other benign abnormality (sclerosing adenosis, & $8(6)$ \\
adenoma, lactational changes, hyperplasia) & \\
No pathologic abnormality & $6(4)$
\end{tabular}

Values within parenthesis are expressed in percentage.

$\mathrm{ADH}$, atypical ductal hyperplasia; ALH, atypical lobular hyperplasia; LCIS, Iobular carcinoma in situ. 
Table 3. Characteristics of Patients Diagnosed with Cancer

\begin{tabular}{|c|c|c|c|c|c|c|c|}
\hline Patient & Age & Family history & Discharge & Physical exam & Radiology & Biopsy & Pathology \\
\hline 1 & 69 & None & $\begin{array}{l}\text { Spontaneous, } \\
\text { unilateral, bloody }\end{array}$ & Normal & $\begin{array}{l}\text { MGM-suspicious } \\
\text { microcalcifications }\end{array}$ & $\begin{array}{l}\text { Core biopsy } \\
\text { of calcs }\end{array}$ & DCIS \\
\hline 2 & 40 & $\begin{array}{l}\text { Three 2nd degree } \\
\text { relatives with breast } \\
\text { cancer, one male }\end{array}$ & $\begin{array}{l}\text { Spontaneous, } \\
\text { unilateral, clear }\end{array}$ & $\begin{array}{l}\text { Excoriated } \\
\text { lesion on nipple }\end{array}$ & $\begin{array}{l}\text { MGM-suspicious } \\
\text { microcalcifications }\end{array}$ & $\begin{array}{l}\text { Punch biopsy } \\
\text { of nipple }\end{array}$ & $\begin{array}{l}\text { Paget's } \\
\text { disease/ } \\
\text { DCIS }\end{array}$ \\
\hline 3 & 34 & $\begin{array}{l}\text { Two 2nd degree relatives } \\
\text { with postmenopausal } \\
\text { breast cancer }\end{array}$ & $\begin{array}{l}\text { Bilateral, expressed, } \\
\text { bloody (on left) }\end{array}$ & $\begin{array}{l}\text { Subareolar } \\
\text { thickening (L) }\end{array}$ & $\begin{array}{l}\text { MGM-normal } \\
\text { U/S-subareolar } \\
\text { mass on left }\end{array}$ & Duct excision & DCIS \\
\hline 4 & 39 & Unknown & $\begin{array}{l}\text { Spontaneous, } \\
\text { unilateral, bloody }\end{array}$ & Nipple inversion & $\begin{array}{l}\text { MGM-normal } \\
\text { U/S-intraluminal } \\
\text { filling defect } \\
\text { DG-filling defect }\end{array}$ & Duct excision & $\mathrm{DCls}$ \\
\hline 5 & 64 & Unknown & $\begin{array}{l}\text { Spontaneous, } \\
\text { unilateral, bloody }\end{array}$ & Normal & $\begin{array}{l}\text { Normal MGM } \\
\text { U/S-dilated ducts } \\
\text { DG-beading of } \\
\text { central duct }\end{array}$ & Duct excision & DCIS \\
\hline 6 & 79 & $\begin{array}{l}\text { Personal history of } \\
\text { contralateral cancer }\end{array}$ & $\begin{array}{l}\text { Spontaneous, } \\
\text { unilateral, bloody }\end{array}$ & Normal & $\begin{array}{l}\text { MGM-normal } \\
\text { U/S-normal. } \\
\text { No DG. }\end{array}$ & Duct excision & DCIS \\
\hline 7 & 37 & None & $\begin{array}{l}\text { Expressed, } \\
\text { unilateral, bloody }\end{array}$ & Normal & $\begin{array}{l}\text { MGM-suspicious } \\
\text { microcalcifications }\end{array}$ & $\begin{array}{l}\text { Core biopsy } \\
\text { of calcs }\end{array}$ & DCIS \\
\hline
\end{tabular}

DG, ductogram; DCIS, ductal carcinoma in situ; MGM, mammogram; U/S, ultrasound.

Table 4. Correlation of Pathology with MGM and US Findings Among Patients Undergoing Tissue Biopsy.

\begin{tabular}{lcc}
\hline & $\begin{array}{c}\text { Normal MGM } \\
\text { and U/S } \\
(n=43)\end{array}$ & $\begin{array}{c}\text { Abnormal finding } \\
\text { on either MGM or } \\
\text { U/S }(n=61)\end{array}$ \\
\hline $\begin{array}{l}\text { Intraductal papilloma or } \\
\text { papillary hyperplasia }\end{array}$ & $19(44)$ & $31(51)$ \\
$\begin{array}{l}\text { Fibrocystic changes } \\
\text { Duct ectasia/inflammatory changes }\end{array}$ & $6(14)$ & $11(18)$ \\
$\begin{array}{l}\text { Cancer } \\
\text { ADH/ALH/LCIS }\end{array}$ & $1(16)$ & $4(6)$ \\
$\begin{array}{l}\text { Other benign abnormality (sclerosing } \\
\text { adenosis, adenoma, lactational } \\
\text { changes, hyperplasia) }\end{array}$ & $3(7)$ & $6(10)$ \\
No pathologic abnormality & $3(7)$ & $5(5)$ \\
& $4(9)$ & $1(2)$
\end{tabular}

Values within parenthesis are expressed in percentage.

$\mathrm{ADH}$, atypical ductal hyperplasia; ALH, atypical lobular hyperplasia; LCIS, lobular carcinoma in situ.

were 104 patients who had a mammogram, ultrasound, and tissue biopsy, for which $43(41 \%)$ had normal studies, whereas $61(81 \%)$ had an abnormality on either mammography or ultrasound. Cancer was diagnosed in $10 \%$ of cases of nipple discharge and an abnormal MGM or US, when compared with $2 \%$ of cases with normal studies. There were 44 patients who had both a ductogram and duct excision, 33 $(72 \%)$ of which were abnormal, reflecting the selective use of ductography at our institution. Table 5 correlates the pathology with the ductography results. There were no cases of cancer when the ductogram
Table 5. Correlation of Ductogram and Pathology Findings Among Patients Undergoing Tissue Biopsy

\begin{tabular}{llc}
\hline & $\begin{array}{c}\text { Normal } \\
\text { ductogram } \\
(n=13)\end{array}$ & $\begin{array}{c}\text { Intraluminal filling } \\
\text { defect or ductal } \\
\text { dilatation }(n=33)\end{array}$ \\
\hline $\begin{array}{l}\text { Cancer } \\
\text { Intraductal papilloma or } \\
\text { papillary hyperplasia }\end{array}$ & $0(0)$ & $2(6)$ \\
$\begin{array}{l}\text { Duct ectasia } \\
\text { Fibrocystic changes }\end{array}$ & $6(46)$ & $22(67)$ \\
ADH/ALH/LCIS & $2(15)$ & $3(9)$ \\
Others & $5(38)$ & $3(9)$ \\
& $0(0)$ & $2(6)$ \\
\hline
\end{tabular}

Values within parenthesis are expressed in percentage.

$\mathrm{ADH}$, atypical ductal hyperplasia; ALH, atypical lobular hyperplasia; LCIS, lobular carcinoma in situ.

was normal, compared with $6 \%$ of cases of an abnormal ductogram, although the small numbers limit any conclusions. Fibrocystic changes were more likely when the ductogram was normal, whereas an intraductal papilloma was more likely when the ductogram was abnormal, although in 6 of the 13 normal ductograms, an intraductal papilloma was present. Overall, one patient with cancer was diagnosed among 46 patients $(2 \%)$ who presented with a suspicious nipple discharge, but had a normal physical examination, mammogram and ultrasound. There were 36 patients who had suspicious discharge, but had no significant family history or personal history of cancer and no findings on physical examination, mammogram or 
ultrasound, which represents $25 \%$ of the population for whom duct excision was recommended.

\section{DISCUSSION}

Nipple discharge is a very common complaint among women, often prompting referral to a surgeon, but only rarely a sign of underlying malignancy. In this series of patients, cancer was present in only $5 \%$ of patients presenting with suspicious nipple discharge. The high percentage of patients referred to our breast care clinic with suspicious nipple discharge $(81 \%)$ probably reflects our referral patterns, with many women having physiologic nipple discharge managed by primary care physicians without a referral to surgery. In addition, many women with nipple discharge undergo directed breast imaging prior to referral to surgery, and in many cases might be diagnosed with cancer prior to referral or be categorized as "abnormal mammogram" or "breast mass." Several studies have estimated the incidence of cancer in the presence of pathologic discharge as between $4 \%$ and $29 \%(1,5-16)$. However, as most of these papers only analyze those patients who ultimately underwent some form of biopsy, the incidence of cancer will vary with the definition of "pathologic nipple discharge", the work-up obtained and the institution's indications for biopsy. In addition, most of the patients included in these series were evaluated over 10-15 years ago, prior to improvements in directed breast imaging.

As the sensitivity of directed breast imaging improves, the fraction of patients with suspicious nipple discharge and negative imaging should decrease, as should the likelihood of malignancy within this population. Among the 46 patients seen at our institution with suspicious nipple discharge and both a normal mammogram and ultrasound, only patient was diagnosed with cancer $(2 \%)$. The one patient who did have cancer despite negative imaging was 79 years of age with a personal history of contralateral breast cancer. In addition, 23 patients with suspicious nipple discharge and normal imaging opted to not undergo excisional biopsy and with a mean follow-up of over 3 years, and none have developed a malignancy.

It is important to point out that this is a single institution study with dedicated breast surgeons and radiologists. However, with such a low incidence of malignancy in the setting of a normal diagnostic mammogram and ultrasound, the practice of routine duct excision for all patients with pathologic nipple discharge can probably be re-examined. Many patients in this setting might still opt for duct excision for palliative purposes. However, a selective approach to duct excision in women who are willing to watch and wait seems very reasonable. Patients at high risk of harboring a malignancy, such as a personal history of breast cancer or strong family history, should be indications for duct excision. Some authors have suggested that the age of the patient should also be taken into consideration. Seltzer reported a cancer incidence of only $1 \%$ among women with nipple discharge less than age 50, and an incidence of $9 \%$ among women 50 years or older (1). Other studies have also reported an increased median age among women with cancer versus those with benign disease $(6,17)$. Using these definitions, our series showed no association with age. However, four of the seven cancer cases were in women $\leq 40$, even though they were only $20 \%$ of patients with suspicious discharge, and this reached statistical significance $(\mathrm{p}=0.03)$. Thus, the importance of a thorough work-up and evaluation of pathologic nipple discharge regardless of age cannot be overemphasized. For women with a completely negative work-up, our data does not support using age alone as a reason to pursue duct excision.

Ductography may be a useful adjunct in the patient with normal mammogram and ultrasound who prefers observation. In our series, among 66 patients with a normal mammogram and ultrasound, a ductogram was attempted in 32 and successful in 24. Of these 24 cases, no abnormalities were found in 10. Seven underwent duct excision, none of whom had cancer, and three opted for observation. For the 14 patient with abnormalities on ductography, most were intraductal papillomas. In our series, our numbers are too small to make any definitive conclusions on the role of ductography in this setting. Adepoju et al. (17). examined the value of breast-imaging studies in patients with nipple discharge and found that individually, mammography, ultrasonography and ductography did not have an adequate sensitivity or specificity to avoid duct excision, but they did not report the incidence of malignancy when all three modalities were negative. Several authors have reported the use of additional modalities beyond mammography, ultrasound, and ductography in the patient with pathologic nipple discharge, such as MR imaging and ductoscopy (14,18-23). Results are mixed, and additional prospective research is necessary to see whether these modalities will allow for a larger percentage of 
women to avoid surgery. It would be expected that a negative $\mathrm{MR}$ in addition to negative conventional imaging would further reduce the probability of malignancy in women during observation. Conversely, false positive MR may subject more women to unnecessary intervention.

In conclusion, among a modern series of patients presenting with suspicious nipple discharge, the incidence of malignancy on duct excision among patients with negative physical examination, and both negative mammography and diagnostic ultrasound, is extremely low. For low-risk patients (without a strong family history or personal history of cancer), short-term observation with repeat imaging and clinical exam is a reasonable approach for those patients who do not desire surgery for palliative purposes. In this series, that would have reduced the number of duct excisions by $25 \%$. Ductography may be helpful in further selecting duct excision versus observation. Patients who develop new findings on exam or repeat imaging, or with persistent nipple discharge, should undergo duct excision.

\section{REFERENCES}

1. Seltzer MH. Breast complaints, biopsies, and cancer correlated with age in 10,000 consecutive new surgical referrals. Breast J 2004;10:111-7.

2. Williams RS, Brook D, Monypenny IJ, et al. The relevance of reported symptoms in a breast screening programme. Clin Radiol 2002;57:725-9.

3. Dixon JM, Mansel RE. ABC of breast diseases symptoms assessment and guidelines for referral. BMJ 1994;309:722-6.

4. Klimberg SV. Nipple discharge: more than pathologic. Ann Surg Oncol 2003;10:98-9.

5. Van Zee KJ, Ortega Perez G, Minnard E, et al. Preoperative galactography increases the diagnostic yield of major duct excision for nipple discharge. Cancer 1998;28:1174-80.

6. Lau S, Kuchenmeister I, Stachs A, et al. Pathologic nipple discharge: surgery is imperative in postmenopausal women. Ann Surg Oncol 2005;12:546-51.
7. Murad TM, Contesso G, Mouriesse H. Nipple discharge from the breast. Ann Surg 1982;195:259-64.

8. King TA, Carter KM, Bolton JS, et al. A simple approach to nipple discharge. Am Surg 2000;10:960-5.

9. Dixon JM. Periductal mastitis/duct ectasia. World J Surg 1989;13:715-20.

10. Cabioglu N, Hunt KK, Singletary SE, et al. Surgical decision making and factors determining a diagnosis of breast carcinoma in women presenting with nipple discharge. J Am Coll Surg 2003;196:354-64.

11. Hou MF, Huang TJ, Liu CG. The diagnostic value of galactography in patients with nipple discharge. Clin Imaging 2001;25:75-81.

12. Wong L, Chung YF, Wong CY. Microdocchectomy for single-duct nipple discharge. Ann Acad Med Singapore 2000;29: 198-200.

13. Vargas HI, Vargas MP, Eldrageely K, et al. Outcomes of clinical and surgical assessment of women with pathological nipple discharge. Am Surg 2006;126:124-8.

14. Morrogh M, Morris EA, Liberman L, et al. The predictive value of ductography and magnetic resonance imaging in the management of nipple discharge. Ann Surg Oncol 2007;14:3369-77.

15. Dawes LG, Bowen C, Venta LA, et al. Ductography for nipple discharge: replacement for ductal excision. Surgery 1998;124:685-91.

16. Locker AP, Galea MH, Ellis IO, et al. Microdochectomy for single-duct discharge from the nipple. Br J Surg 1988;7:700-1.

17. Adepoju LJ, Chun J, El-Tamer M, et al. The value of clinical characteristics and breast-imaging studies in predicting a histopathologic diagnosis of cancer or high-risk lesion in patients with spontaneous nipple discharge. Am J Surg 2005;190:644-6.

18. Louie LD, Crowe JP, Dawson AE, et al. Identification of breast cancer in patients with pathologic nipple discharge: does ductoscopy predict malignancy? Am J Surg 2006;192:530-3.

19. Liu G-Y, Lu J-S, Shen K-W, et al. Fiberoptic ductoscopy combined with cytology testing in the patients of spontaneous nipple discharge. Breast Cancer Res Treat 2007;108:271-7.

20. Moncrief RM, Nayar R, Diaz LK, et al. A comparison of ductoscopy-guided and conventional surgical excisioin in women with spontaneous nipple discharge. Ann Surg 2005;241:575-81.

21. Tjalma WAA, Verslegers IOJ. Nipple discharge and the value of MR imaging. Eur J Obstet Gynecol 2004;115:234-6.

22. Orel SG, Dougherty CS, Reynolds C, et al. MR imaging in patietns wtih nipple discharge: initial experience. Radiology 2000;216:248-54.

23. Yoshimoto M, Kasumi F, Iwase $\mathrm{T}$, et al. Magnetic resonance galactography for a patient with nipple discharge. Breast Cancer Res Treat 1997;42:87-90. 